\title{
CIEN AÑOS DESPUÉS Y VARIAS EPIDEMIAS MÁS TARDE LLEGÓ LA COVID-19
}

\section{A Hundred Years Later and Several Epidemics Later, COVID-19 Arrived}

\author{
Agustín HIDALGO \\ Área de Farmacología, Departamento de Medicina, Universidad de Oviedo. Instituto Universitario de Oncología \\ del Principado de Asturias. Instituto de Investigación Sanitaria de Asturias (España). \\ Correo electrónico: hidalgo@uniovi.es
}

Fecha de recepción: 15 de octubre de 2020

Fecha de aceptación: 16 de octubre de 2020

Fecha de publicación: 29 de enero de 2021

La enfermedad es algo inesperado que, generalmente, llega a destiempo según la percepción de la propia existencia. A veces es tan abrupta y exigente que no da lugar a disponer de un tiempo de reacción para ordenar los recursos y el propio ánimo para combatirlas. Esto ha ocurrido con la pandemia por la COVID-19, cien años después de la denominada gripe española. Ha llegado de sopetón, ha puesto patas arriba a todo el sistema de salud, se ha cobrado vidas y recursos cual peste de otros tiempos, y nuestra forma de vivir se ha visto afectada en prácticamente todos sus aspectos. Es la última gran epidemia de las muchas que han afectado al ser humano en los últimos cuarenta años en los que hemos visto el SIDA, el Ébola, el SARS, la H1N1, El MERS, la Gripe Aviar y, ahora, la COVID-19. Los virólogos sabían que podía ocurrir otra pandemia y algunos la estaban esperando desde que empezó el siglo XXI. No descartaban que tuviera un origen zoonótico y para ello se habían dispuesto protocolos epidemiológicos a nivel mundial sobre la forma de afrontarla. Sin embargo, todo ha sido desbordado, hemos tenido la desgracia de una conjunción "astral» de mandatarios tan indocumentados como populistas que se han atrevido a negar las evidencias y a ignorar medidas prudentes. No en vano Siri Hustvedt advierte: «Las ideas virales no tienen impacto sobre la enfermedad viral. Al virus no le intimidan las fanfarronadas o los postureos racistas o machistas, ni la grandilocuencia antiintelectural $»^{1}$.

La enfermedad COVID-19 ha guardado algunas similitudes con las grandes pandemias históricas ${ }^{2}$, es decir, ha venido de fuera, ha llegado siguiendo las rutas comerciales, la ha generado 
un germen esquivo que se resiste a mostrar sus modos de atacar dificultando de esta forma la réplica terapéutica, ha afectado a un número considerable de personas con preferencia por las de salud más crítica y por los más desfavorecidos, ha causado muertes dolorosas, ha puesto en compromiso la capacidad de respuesta de los Estados, ha inducido al confinamiento y ha generado miedo y algún atisbo de pánico en la ciudadanía. Y, como también indica Susan Sontag, hemos vuelto a recurrir a la terminología bélica porque la infección es la agresión de un elemento externo (lo que nos tenemos bien ganados por ser el hombre un sistema biológico abierto) ${ }^{3}$ a la que combatimos con todo el arsenal disponible a nuestro alcance con el fin de ganar la "guerra» al coronavirus.

A lo largo de la pandemia no han faltado autores de renombre, como Siri Hustvedt, Premio Princesa de Asturias de las letras 2019, que han narrado su enfermedad y/o confinamiento en diferentes partes del mundo. Tampoco han faltado novelas sobre el tema como En tiempos de contagio de Paolo Giordano, ni lecturas desde la filosofía por parte de Slavoj Zizek con Pandemia, ni series televisivas a las que seguirán obras cinematográficas de mayor calado, representaciones teatrales y, en otras manifestaciones artísticas, ni una inabarcable sucesión de títulos sobre el tema.

La historia oficial, como es conocida, empieza con la comunicación de las autoridades de China a la Organización Mundial de la Salud, el día 31 de Diciembre de 2019, de la existencia de un foco de neumonía no filiada en la ciudad china de Wuhan. Desde entonces, la imagen de una ciudad confinada, de las fronteras cerradas y las calles vacías, de las curvas de afectados y muertos y de los mapas de extensión de la epidemia, de su transformación oficial en pandemia y de la increíble falta de coordinación internacional en el control de la misma se han sucedido día a día en los medios de comunicación de masas y en las comunicaciones oficiales de los organismos internacionales.

Para cuando la enfermedad termine su ciclo anual, se habrán visto afectados los ciudadanos de todos los países en los que, también, se habrán producido muertes (hay contabilizados más de un millón de fallecidos cuando se redacta esta editorial) y afectado todos los sistemas sociales, desde la educación a la economía, con estragos más o menos manifiestos aparentemente relacionados con la celeridad de la instauración de las medidas, con el nivel científico de las naciones, con la disciplina de los ciudadanos y con el sentido común de las autoridades políticas y administrativas de cada país.

La afectación creciente de países, la pronunciada curva de contagios, la mortalidad, el desconocimiento de la biología del virus y la inexistencia de un tratamiento eficaz a corto plazo motivó la adopción de medidas a nivel mundial que han tenido importantes repercusiones en un amplio abanico de los ámbitos de la organización social. De todas ellas, y en consonancia con la línea editorial de la Revista de Medicina y Cine, traemos a este número extraordinario dedicado a Epidemias y Pandemias una serie de 40 artículos que pueden agruparse en cuatro grandes apartados: a) Formación en tiempos del coronavirus; b) Respuesta sanitaria y valores profesionales; c) Historia y vivencia de las epidemias; y d) Manifestaciones sociales y artísticas de las epidemias y pandemias.

El primer apartado está relacionado con la formación en tiempos del coronavirus y del post COVID-19. Su irrupción en la enseñanza fue abrupta. La actividad académica quedó paralizada por el confinamiento y hubo de adaptar las metodologías, procesos y técnicas a la nueva situación de confinamiento y teletrabajo. La COVID-19 ha impuesto nuevos hábitos en la docencia y exigido a profesores y estudiantes esfuerzos renovados y la adaptación a la enseñanza en un entorno virtual. La enseñanza universitaria, de la que la 
formación en Medicina no ha sido una excepción, siguió los mismos derroteros y ha sido objeto de algunas editoriales $\mathrm{s}^{4,5} \mathrm{y}$ artículos que informan de la percepción de profesores y estudiantes ${ }^{6}$ y de experiencias en situaciones similares ${ }^{7}$. A la vez, va ganando adeptos la opción de que esta crisis debe aprovecharse para profundizar las reformas de la formación médica que ya están en marcha y acometer una reflexión en profundidad sobre la adaptación de los planes de estudios de grado, postgrado y formación especializada a las demandas de salud de la población ${ }^{8,9}$. Algunas de estas modificaciones se quedarán definitivamente entre las técnicas educativas y, posiblemente, animarán la llegada de otras, lo que conferirá un mayor peso de la enseñanza virtual y del adiestramiento instrumental antes de acceder a la práctica clínica, sin olvidarse del necesario empuje que debe aplicarse a la educación humanística de los futuros médicos que han de implementar su formación en empatía.

Sin embargo, este canto liberador de las tecnologías debe ser matizado. El desarrollo tecnológico actual está produciendo un nuevo cambio paradigmático, tal vez un nuevo giro copernicano en el que el hombre es relegado en el papel de generador de conocimiento en favor de las máquinas. El hombre actual debe regirse por datos, y este dataismo, amenaza al humanismo porque "la producción de saber impulsada por datos se hace sin sujeto humano ni conciencia. (...) Los procesadores son más rápidos que el hombre justamente porque no piensan ni comprenden, sino que se limitan a calcular ${ }^{10}$. En qué medida esta transformación afectará a la formación en Medicina y en Ciencias de la Salud, forma parte del futuro remoto, una vez que se concrete el transhumanismo y la adquisición de consciencia por las máquinas ${ }^{11}$ y trascienda el papel instrumental que ahora ofrecen.

Bajo el epígrafe de Respuesta sanitaria y Valores profesionales hemos reunido artículos que describen cómo la pandemia por la COVID-19 ha exigido un esfuerzo añadido a los sistemas de salud que se han visto tensionados, tanto en la atención hospitalaria como a nivel de la atención primaria, por la escasez de recursos materiales y humanos. Todo ello, ha tenido repercusiones en los valores profesionales, en la percepción del riesgo, en cómo se ha contado la pandemia en los medios a lo largo del periodo álgido, en el que la COVID-19 y sus consecuencias han ocupado más del $70 \%$ de toda la información accesible en los medios de comunicación, llegando a convertirse en un monotema y provocando la saturación y el hastío de los ciudadanos. En contra de la categorización mediática que ha atribuido al personal sanitario la calificación de héroes, pensamos que este personal no ha hecho otra cosa que poner en juego los valores de la medicina y de otras profesiones sanitarias, que las han ejercido como lo que son, profesionales vocacionales, altruistas, empáticos y comprometidos con el bienestar del enfermo, valor supremo al que se dirigen las actuaciones de los profesionales sanitarios ${ }^{12}$.

La respuesta sanitaria y científica a esta pandemia nos ha enfrentado a problemas bioéticos de primera magnitud que ha exigido pronunciamientos y consensos desde la legislación y la práctica clínica. En síntesis, nos ha obligado a cambiar la leyenda de que teníamos la mejor sanidad del mundo por la de una sanidad eficiente en condiciones basales.

Por otra parte, también se ha explorado cómo se ha contado la pandemia, quien la contaba, cuál era el nivel de compromiso del narrador, los aspectos que se narran, etc., porque las noticias tienen la inmediatez y la rapidez de exposición a hechos incidentales con los que no puede competir otro texto documental, y menos un libro de texto. La comunicación es uno de los aspectos que se consideran en la Revista de Medicina y Cine y, dentro de esta, un aspecto muy relevante es la comunicación en salud con una especialización creciente en los medios ${ }^{13,14}$. Se suele decir que los medios "construyen» la 


\section{CIEN AÑOS DESPUÉS Y VARIAS EPIDEMIAS MÁS TARDE LLEGÓ LA COVID-19}

AGUSTÍN HIDALGO

realidad cotidiana a través de sus comentarios sobre hechos significativos de la misma ${ }^{15,16}$. Si bien no está establecido el grado en que esto es así, no es menos cierto que la mayoría de las personas acceden a la información en salud a través de los medios, a través de los que hemos asistido a lo largo de estos meses a la creación de una conciencia social de responsabilidad frente a la COVID-19 en la que pueden identificarse de forma nítida los componentes científicos, económicos, políticos y sociales que acompañan al problema de salud, así como las formas en que se relacionan entre ellos con importantes áreas para la discusión crítica y las diatribas partidarias, y la emergencia de líderes médicos en la gestión.

Bajo el epígrafe de historia y vivencia de las epidemias, hemos incluido artículos que se aproximan al problema con una perspectiva histórica. Decíamos antes que las epidemias/ pandemias han convivido con el hombre desde la antigüedad. Actualmente, buena parte de estas enfermedades pandémicas son zoonosis identificables $y$, generalmente, bien descritas. $Y$ con seguridad que estas zoonosis seguirán ocupando un papel relevante en la patología infecciosa. Pero no existen epidemias únicamente de origen infeccioso, también las hemos tenido de envenenamiento por productos naturales y por toxicidad de medicamentos. La historia ${ }^{17}$ nos ofrece una perspectiva de los esfuerzos realizados en todas las culturas para intentar controlar los efectos en los ciudadanos, las instituciones y el tejido productivo. También, nos ofrece una serie de pautas de abordaje (aislamiento, distancia, medidas paliativas, purificación de estancias, utilización de los recursos del momento) que se han repetido a través de los tiempos.

La última sección, referida a manifestaciones sociales y artísticas, agrupa un buen puñado de artículos relacionados con las repercusiones que las epidemias y pandemias han tenidos en la historia, la política, la literatura o el arte cuya autoría se reparten colaboradores habituales de la revista y firmas que se estrenan, todas alineadas con la apuesta de la Revista de Medicina y Cine por el humanismo médico.

De forma similar a lo que estamos viviendo actualmente con la pandemia por COVID-19, las enfermedades que afectan a una parte sustancial de la población y producen mortalidad añadida inducen modificaciones sociales que, con frecuencia, tienen repercusiones en las manifestaciones artísticas, de lo que dan buena muestra la abundante repercusión en la pintura y la escultura a lo largo de la historia. Pero también, la literatura ha recurrido a la enfermedad con diferentes objetivos: representar la realidad, recrear una situación para extraer enseñanzas, educar a la ciudadanía, analizar la representación de la figura sanitaria, las actitudes institucionales,..., mediante construcciones épicas, naturalistas o metafóricas, y a través de géneros como la poesía, la novela, el ensayo o el teatro. Sin embargo, el inmenso caudal de comunicación que aporta el cine, con argumentos basados en textos literarios o elaborados ad hoc, en sus diferentes formatos, le ha convertido en un elemento indispensable para la difusión del conocimiento en salud, del sentido atribuido a las epidemias y del abordaje institucional y ciudadano de las mismas.

A lo largo de los artículos que componen este número extraordinario coexisten narrativas de diferente índole, la cinematográfica, la literaria, la histórica, la que aporta el arte; interpretaciones de procesos que han causado gran sufrimiento a la humanidad. Los artículos relacionados con estos procesos narrativos dejan constancia de la enfermedad como castigo divino, la superstición, la abnegación de los sanitarios que les lleva a arriesgar sus vidas, el correcto uso del conocimiento médico del momento y la gestión de la incertidumbre en la atención al paciente, las limitaciones de su actividad por las condiciones políticas y sociales, y el papel de las familias con sufrimiento de vergüenza y culpa, que, a lo largo de la historia ha condicionado, aún más, la 


\section{CIEN AÑOS DESPUÉS Y VARIAS EPIDEMIAS MÁS TARDE LLEGÓ LA COVID-19 AGUSTÍN HIDALGO}

marginación y la estigmatización de los enfermos. Esto es visible en las narraciones literarias y cinematográficas, en los estudios históricos y en las manifestaciones artísticas de epidemias de cólera, lepra, poliomielitis, viruela, gripe española, peste negra, ébola, o peste neumónica, junto a supuestas epidemias virales genéricas por gérmenes desconocidos y las recientes distopías víricas tan del gusto actual.

Este inmenso caudal puede ser utilizado, como propone la línea editorial de la Revista de Medicina y Cine, para la educación para la salud de la ciudadanía y para la formación de los estudiantes de ciencias de la salud.

\section{REFERENCIAS}

1. Hustvedt S. Vivo con miedo, imagino el futuro. El País. Suplemento Babelia,[Internet] 4 de abril de 2020.

2. Sontag S. La Enfermedad y sus metáforas. El SIDA y sus metáforas. Barcelona: DeBolsillo; 2013.

3. Mayr E. Así es la biología. Madrid: Debate; 1995.

4. Millán Núñez-Cortes, J. Educación médica mediante la crisis por Covid-19. Educ Med. 2020; 21(3): 157.

5. Costa MJ, Carvalho-Filho M. Una nueva etapa para la educación médica después de la COVID-19. FEM 2020; 23(2): 55-7.

6. Rojo Martínez JM, Conesa Erragbaoui AG, Vera Villalba J, García García MA, Martínez de Rituerto Rey $P$, et al. Encuesta sobre docencia online en las Facultades de Enfermería y Medicina de la Universidad de Murcia durante COVID-19. Rev Esp Edu Med 2020;1(1): 24-31.
7. Vergara de la Rosa E, Vergara Tam R, Álvarez Vargas M, Camacho Saavedra L, Galvez Olortegui J. Educación médica a distancia en tiempos de COVID-19. Educ Med Super. 2020; 34 (2): e2383.

8. Gual A. Repercusión de la COVID-19 en la educación de los médicos: de la formación al aprendizaje (I). FEM 2020; 23(3): 103-5.

9. Casademont J. Reflexiones de un docente ante la situación de pandemia de COVID-19. FEM 2020; 23(3): 107- 9.

10. Han B-C. La desaparición de los rituales. Barcelona: Herder; 2020.

11. Bartra R. Chamanes y robots. Barcelona: Anagrama; 2019.

12. Millán Núñez-Cortes JM, del Llano-Señaris J del. Ser médico. Los valores de una profesión. Madrid: Unión Editorial; 2013.

13. Revuelta G. Salud y medios de comunicación en España. Gac Sanit 2006; 20 (Supl 1):203-8.

14. Camacho-Markina I. La 'gripe A', en la prensa española. Revista Latina de Comunicación Social 2009; 64:827-43.

15. Elías C. Formatos mediáticos de la información científica: prensa, periódicos digitales, radio y televisión. En: Elías C. Fundamentos del periodismo científico y divulgación mediática. Madrid: Alianza Editorial; 2008. p. 187-231.

16. Camacho Markina I (Coord.). La especialización en el periodismo. Zamora: Comunicación Social Ediciones y Publicaciones; 2010.

17. Maradona Hidalgo JA. Historia de las enfermedades infecciosas. Oviedo: Universidad de Oviedo; 2010. 